\title{
Distal aphalangia, microcephaly and mental retardation
}

\section{VP Wickramasinghe ${ }^{1}$, Sanath P Lamabadusuriya ${ }^{2}$ and Navodha Athapattu ${ }^{3}$}

(Index words: Distal aphalangia, microcephaly, seizures, consanguinity, mental retardation)

\section{Case history}

A 3-year old boy from Hatton presented with generalised convulsions. He was the third child born to consanguineous parents. The antenatal and perinatal period of this child had been normal. At 3 months of age he developed generalised convulsions and was treated with phenobarbitone at the Nawalapitiya Base Hospital. However, subtle seizures persisted at a frequency of about 1 or 2 seizures a month. At about 15 months of age the seizure frequency increased. He also had global development delay.

On examination he had dysmorphic features. The occipito-frontal circumference was $46 \mathrm{~cm}(<3$ rd centile, [1], length of child $89 \mathrm{~cm}(<3 \mathrm{rd}$ centile $)$ and weight 13.5 $\mathrm{kg}$ (between 10th and 25th centile).

The dysmorphic features were mainly confined to hands and feet. The distal phalanges of all the four fingers of the right hand and fourth and fifth of left hand were hypoplastic. All affected fingers showed some degree of camptodactyly and nails were absent. Both thumbs and, left index and middle fingers appeared normal (Figure 1). Xray of the hand revealed that the distal phalanges of the affected fingers were absent. The distal phalanx of the left index finger was hypoplastic. Other bones of the both hands were normal.

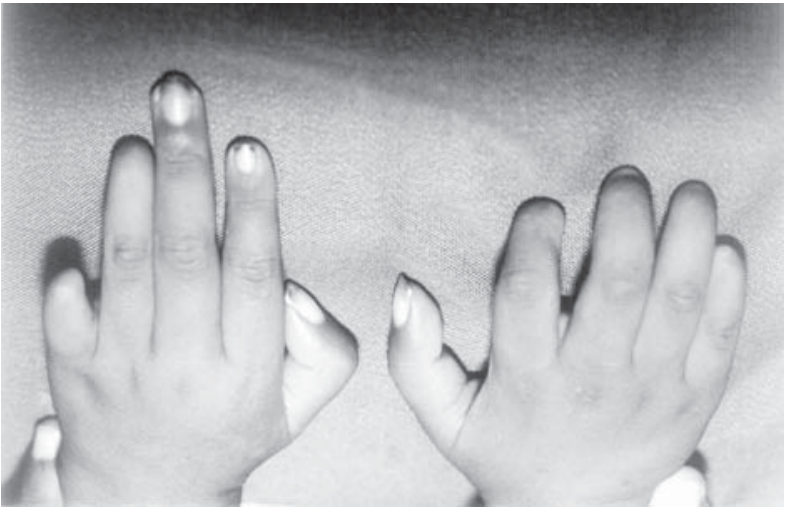

Figure 1. Hands of the patient.

All toes appeared short. There was overriding of the left fourth toe. Toenails appeared normal (Figure 2). Xray of both feet showed that there were only two phalanges in each toe. Phalanges of both big toes were normal in size and shape. The distal phalanges of all other toes were hypoplastic (acro-osteolysis). There was duplication of the proximal phalanx of fourth toe (Figure 3). Neither hands nor fingers showed polydactyly or syndactyly.

He had generalised hypotonia and global development delay. He could sit without support but could not stand. He reached out for objects but the pincer grasp was poor.

${ }^{1}$ Lecturer, ${ }^{2}$ Senior Professor, Department of Paediatrics, Faculty of Medicine, University of Colombo; ${ }^{3} \mathrm{House}$ Officer, Professorial Paediatric Unit, Lady Ridgeway Hospital, Colombo.

Correspondence: VPW, e-mail: <pujithaw@yahoo.com> (Competing interests: none declared). Received 19December 2003 and revised version accepted 20 January 2004. 
He could only babble. His hearing was poor with a failed distraction test.

We were able to examine only the index case. The parents and siblings could not come to our hospital. According to the guardian of the child other family members were normal in physique and intelligence.

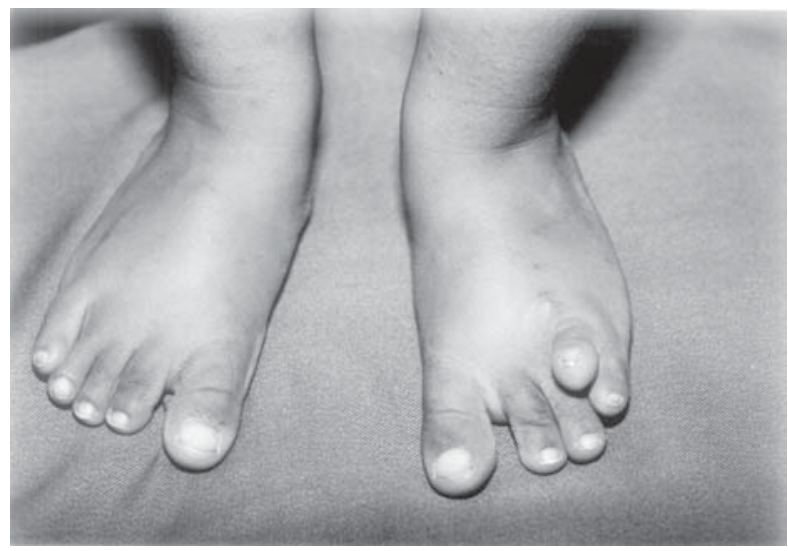

Figure 2. Feet of the patient.

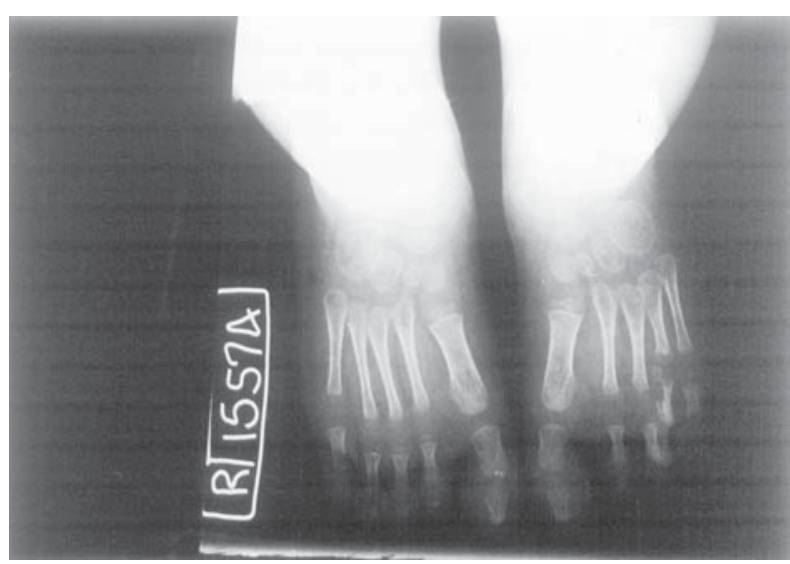

Figure 3. Xray of the feet.

\section{Discussion}

A literature search (PubMed, National Library of Medicine, USA) was done with the key words, distal aphalangia, microcephaly and short stature. It provided only two documented case histories [2,3]. The first case described three members of a family (father and two siblings; a boy and a girl) from Spain. The clinical features they had were partial aphalangia, syndactyly with duplication of metatarsal, microcephaly, short stature and low intelligence. The condition was thought to be of autosomal dominant inheritance [2]. The second case with some of these features was in a 17-year old boy [3]. There was consanguinity of parents suggesting the possibility of an autosomal recessive inheritance.

The child we have described could be the third case reported in the literature. The consanguinity of parents suggests an autosomal recessive pattern of inheritance, but the possibility of autosomal dominant inheritance due to a fresh mutation cannot be excluded.

\section{References}

1. Kucmarski RJ, Odgen CL, Grummer-Strawn LM, Flegal KM, Guo SS, et al. CDC Growth Charts: United States. Advance Data 2000; 314:1-28.

2. Martinez-Frias ML, Martin M, Pardo M, Fernandez de las HF, Frias JL. Distal aphalangia, syndactyly, and extra metatarsal, associated with short stature, microcephaly, and borderline intelligence: a new autosomal dominant disorder. American Journal of Medical Genetics. 1995; 16: 213-6.

3. Di Rocco M. Distal aphalangia, an extra metatarsal, short stature and microcephaly: a second case. Clinical Dysmorphology 2002; 11: 295-6. 